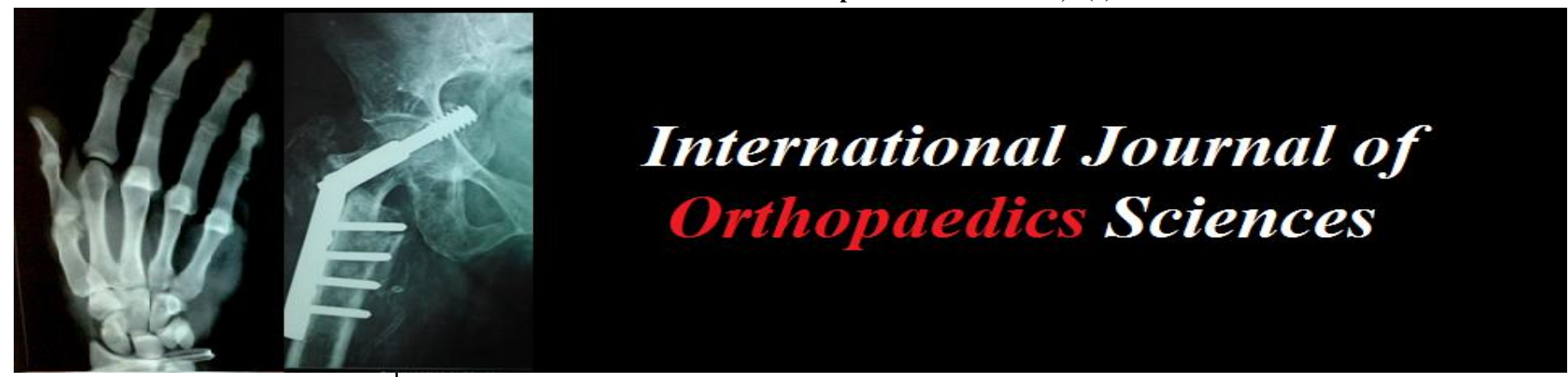

ISSN: $2395-1958$

IJOS 2018; 4(4): 752-754

(C) 2018 IJOS

www.orthopaper.com

Received: 05-08-2018

Accepted: 10-09-2018

Dr. Surendra Singh Yadav Associate professor, Deptt. Of orthopaedics Gajraraja medical college, Gwalior, Madhya

Pradesh, India

Dr. Sonendra Kumar Sharma Senior resident, Deptt. Of orthopaedics Gajraraja medical college, Gwalior, Madhya

Pradesh, India
Correspondence

Dr. Sonendra Kumar Sharma Senior resident, Deptt. Of orthopaedics Gajraraja medical college, Gwalior, Madhya

Pradesh, India

\section{Functional outcome of titanium elastic nailing for pediatric femoral shaft fracture}

\section{Dr. Surendra Singh Yadav and Dr. Sonendra Kumar Sharma}

DOI: https://doi.org/10.22271/ortho.2018.v4.i4j.93

\section{Abstract}

Background: Femoral shaft fracture is comman injury among children's. The comman cause of injury is either motor vehicle accidents or sport trauma, physical assault or some other rare causes. Usually it is treated conservatively in small children's but in adolescents intra-medullary nailing with TENS nail is gaining popularity so we have selected this age group's femoral shaft fracture for further exploration in our study.

Results: Femoral shaft fracture's treatment with TENS nailing is gaining popularity because of comparative easy, minimal invasive and less time consuming procedure with good functional and radiological outcomes.

In our study, final outcome was excellent in 16 cases $(72.7 \%)$, satisfactory in 5 cases $(22.7 \%)$ and poor in only 1 case $(4.5 \%)$.

Conclusion: Based on our study, our conclusion is that close reduction and internal fixation with titanium elastic nailing is standard method of treatment in femoral shaft fracture in children's between 414 years of age group as it is minimal invasive, less time consuming procedure without any damage to growth plate in growing child's which provides comparatively stable fixation. It also allows early mobilization which helps in early bony union.

Keywords: children's, fracture, shaft femur, TENS nail, close reduction

\section{Introduction}

Femoral shaft fracture is comman injury among children's, which is around $1.6 \%$ of all bony injuries in children's ${ }^{[1]}$. The comman cause of injury is either motor vehicle accidents or sport trauma, physical assault or some other rare causes ${ }^{[2]}$ The aim of treatment of femoral shaft fracture is anatomical realignment with proper functioning of hip and knee joints. Traditionally femoral shaft fracture in children's younger than 4 years are treated conservatively because of power of rapid healing and spontaneous correction of angulation in most of children's and in children's more than 14 years of age it is treated with intra-medullary nailing with satisfactory results. But in age group between 4-14 years of age where intra-medullary nailing can't be done because of skeletal immaturity and also conservative treatment may leads to loss of reduction, limb length discrepancy, defortmities, malunion and other psychosocial complication of plaster application, also elder children's not tolerate plaster application for long duration. So in this age group of children's Titanium elastic nailing system gaining popularity because of comparative stable elastic fixation, comparative easy and minimal invasive procedure without damaging growth potential of growing children's ${ }^{[3]}$.

\section{Aims and Objectives}

Aim of the study was to assess the functional and clinical outcome after closed reduction and internal fixation with titanium elastic nail in femoral shaft fractures of children's between 4 to 14 years of age.

\section{Materials and Methods}

This was a prospective study conducted at the Department of Orthopedic Surgery, Gajra raja medical college, Gwalior (Madhya Pradesh) during period of July 2016 to June 2017. Study was done in all children between 4-14 years of age irrespective of sex with shaft femur 
Fractures meeting the following inclusion and the exclusion criteria.

\section{Inclusion Criteria}

1. Age between 4-14 years

2. children's of both sex

3. Diaphyseal fracture

4. close fracture

5. Children's where follow up is possible for minimum 6 months.

\section{Exclusion Criteria}

1. Age less than 4 years and more than 14 years

2. Metaphyseal fracture

3. Open fractures, pathological fracture

4. Fracture with other associated injuries

5. Children's who have lost follow up within 6 months.

After admission of all the children's with femoral shaft fracture in emergency ward vitals stabilization was done and fracture were temporarily stabilized by skin traction or Thomas splint. Plain radiographs was taken in both AP and Lateral views with hip and knee joints, written informed consent was taken from parents, who fulfills our inclusion criteria for inclusion in study and patients were prepared for surgery. All the preoperative investigations and pre anaesthetic checkup was done. All patients were operated as early as possible once the patients become fit for surgery. Diameter of nail were calculated using Flynn"s formula.
Flynn et al.'s formula. (4)

Diameter of nail=width of the narrowest point of the medullary canal on Antero-posterior and lateral view $\mathbf{X}$ $0.4 \mathrm{~mm}$

Patients were operated using traction table under fluoroscopic guidance. After proper reduction of fracture, small skin incision was given on both medial and lateral side of distal thigh around $2 \mathrm{~cm}$ proximal to distal epiphyseal plate. Than titanium elastic nail of proper size $(2-3.5 \mathrm{~mm})$ with curve ends were introduced from both medial and lateral side simultaneously till fracture site after it one nail was passed across the already reduced fracture site followed by another one. The nails were progressed in such a ways that medial side nail was introduced in to the neck of femur just below the physis and lateral nail was progressed just below the trochanter physis. After satisfactory reduction and positioning of nails there ends were bent in such a ways that they never project beyond distal epiphysis plate on IITV and also there ends should not be sharp otherwise they may irritates the skin. Finally introduction site were closed.

Postoperatively patients were encouraged quadriceps strengthening and knee bending exercises as soon as patients can tolerate (usually within 24 hours of surgery) and for few days patients was kept non-weight bearing than partial weight bearing allowed depending on the stability of fracture and callus formation but full weight bearing was allowed only after radiological evidence of firm union. Patients was followed at 2, 6, 12 and 24 week. The final outcome based on the above observations was done as per Flynn's criteria (Table 1). (5)

Table 1: Flynn's criteria \# TENS Outcome score

\begin{tabular}{|c|c|c|c|}
\hline Results variables at 24 Weeks & Excellent & Satisfactory & Poor \\
\hline Limb length inequality & $<1.0 \mathrm{~cm}$ & $<2 \mathrm{~cm}$ & $<2 \mathrm{~cm}$ \\
\hline Mal-alignment & 5 degree & 10 degree & $>10$ degree \\
\hline Unresolved pain & Absent & Absent & Present \\
\hline Other complications & None & Minor and resolved & Major and lasting \\
\hline
\end{tabular}

\section{Results}

In our study total 22 patients with shaft femur fracture were operated between July 2016 to June 2017 with titanium elstic nailing at deptt. Of orthopedics, Gajra raja medical college, Gwalior, Madhya Pradesh. There were 14 boys and 8 girls and all children's were between ages of 4 to 15 years. Most of the patients (18) patients had motor vehicle accident as mode of injury, 3 pateints had fall from height while playing, 1 patients was with physical assault. No case with bilateral and segmental fracture was seen. In all patients 17 patients were having midshaft fracture, 3 patients were present with proximal femur fracture, 2 patients were present with distal femur fracture. In $64 \%$ cases (14) right side was involved. In our study transverse fracture were present in 12 patients, oblique fracture in 7 patients and spiral fracture in 3 patients. All of our patients underwent surgery within 7 days of trauma and duration of surgery was less than 60 minutes in all cases. All cases were operated in a closed manner with small incision and minimal blood loss. Average stay in hospital is around 3.5 days.

In our study union was achieved in $<3$ months in $16(73 \%)$ patients and 3-6 months in $6(27 \%)$ patients with average time of union was 11 weeks. Full weight bearing was started in 10 weeks in most of the patients and also full movements was achieved in 10 weeks in most of the patients.

Results were excellent in $16(72.7 \%)$ patients, satisfactory in $5(22.7 \%)$ patients, poor in $1(4.5 \%)$ patients as per FLYNN

\section{Criteria ${ }^{[5]}$.}

Complications: One patient has nail protrusion due to long nail and which was removed at $4^{\text {th }}$ month after fracture union. No deep infection, no angular or rotational deformity, no limb length discrepancy, pain, limp or gait abnormality occurs in any patient.

\section{Discussion}

In our study average age is 8.5 year. In study done by Flynn JM et al. mean age was 10.2 years ${ }^{[6]}$. Sex incidence of our study is 14 boys $(63.6 \%)$ and 8 girls $(36.3 \%)$, which is also comparable with study as Bhasker et al. which examined total 60 patients with $63.4 \%{ }^{[38]}$ were boys and $36.6 \%{ }^{[22]}$ were girls [7]. In our study motor vehicle accident is main mode of injury with total $81.8 \%{ }^{[18]}$ patients, and in our comparative study of Flynn et al. was having $58.1 \%$ cases with RTA and other cases with fall from height or physical assault ${ }^{[6]}$. In our study increased incidence of RTA may be due to recent increase in no. of vehicles in developing country, poor road conditions and lack of street light or untrained drivers. Average duration of surgery in our study is less than 60 minutes, which is comparable with study done by Saikia et al. where duration of surgery ranged from 50-120 minutes with average was 70 minutes ${ }^{[1]}$.

In our study average time of union is 11 weeks, whereas Saikia et al. reported average union time as 8.7 weeks and 
Bhasker et al. reported 12 weeks ${ }^{[1]}$.

In our study we started weight bearing by average $10^{\text {th }}$ weeks wheras Saikia et al. allowed weight bearing average by 8.8 weeks ${ }^{[2]}$.

In our study only 1 patient developed pain at the site of entry due to nail protrusion which was resolved after nail removal at $4^{\text {th }}$ month, Flynn et al. also reported pain at site of insertion in around $16.2 \%$ of cases with nail insertion ${ }^{[5]}$. None of our patient developed deep infection, rotational or angular deformity or limb length discrepancy whereas Khazzam et al. reported overgrowth of more than $2 \mathrm{~cm}$ in 3 patients and Flynn et al. reported 10 cases with minor angulation ${ }^{[3]}$.

In our study, final outcome was excellent in 16 cases $(72.7 \%)$, satisfactory in 5 cases $(22.7 \%)$ and poor in only 1 case (4.5\%). Flynn et al. had excellent outcome in $65 \%$ cases, satisfactory in $25 \%$ cases and poor in $10 \%$ cases, Saikia et al. also reported excellent outcome in 59\%, satisfactory in $27.2 \%$ and poor in $13.6 \%$ cases in their studies. $(2,5)$.

\section{Conclusions}

Based on our study, our conclusion is that close reduction and internal fixation with titanium elastic nailing is standard method of treatment in femoral shaft fracture in children's between 4-14 years of age group as it is minimal invasive, less time consuming procedure without any damage to growth plate in growing child's which provides comparatively stable fixation.it also allows early mobilization which helps in early bony union

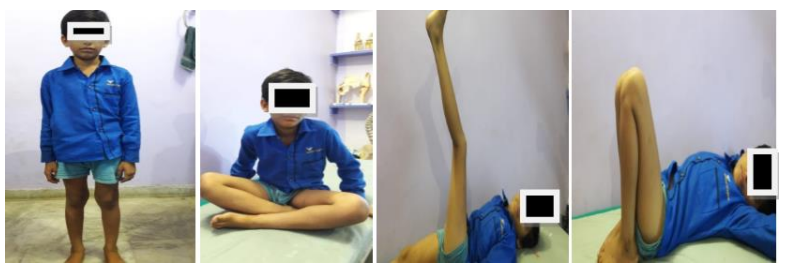

Fig 1: Clinical photographs of patient treated with TENS nailing for shaft femur fracture

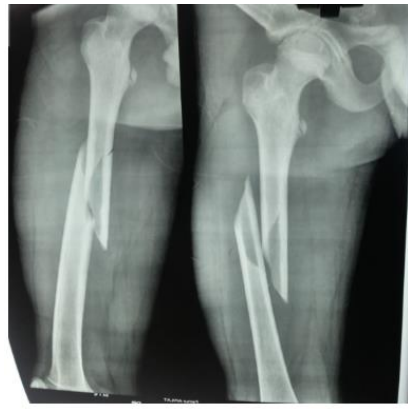

Pre-op x ray

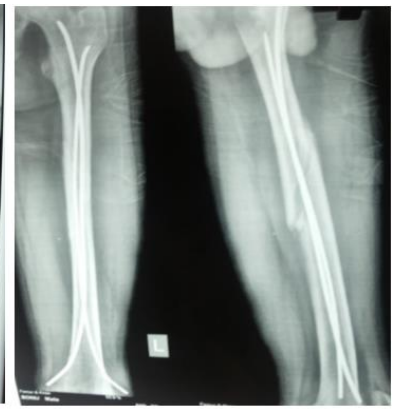

2 week post op $x$ ray

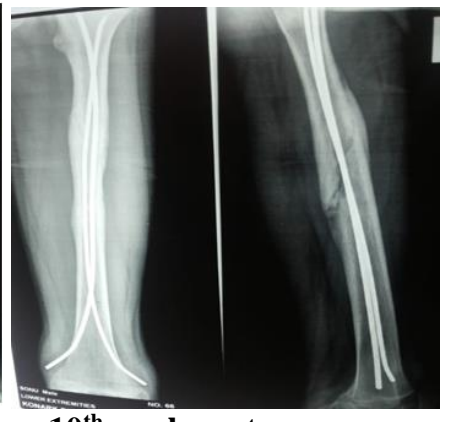

$10^{\text {th }}$ week post op $x$ ray

\section{References}

1. Saikia KC, Bhuyan SK, Bhattacharya TD, Saikia SP. Titanium elastic nailing in femoral diaphyseal fractures of children in 6-16 years of age. Indian J Orthop. 2007; 41(4):381-5.

2. Viljanto J, Linna MI, Kiviluoto $H$, Paananen $M$. Indications and results of operative treatment of femoral shaft fractures in children. Acta Chir Scand. 1975; 141(5):366-9.

3. El-Adl G, Mostafa MF, Khalil MA, Enan A. Titanium elastic nail fixation for paediatric femoral and tibial fractures. Acta Orthop Belg. 2009; 75(4):512-20.

4. Flynn JM, Skaggs DL, Sponseller PD, Ganely TJ, Kay RM, Kellie Leitch KK. The operative management of pediatric fractures of lower extremity. J Bone Joint Surg Am. 2002; 84:2288-300.

5. Flynn JM, Hresko T, Reynolds RA, Blaiser RD, Davidson R, Kasser J. Titanium elastic nails for pediatric femur fractures: a multicenter study of early results with analysis of complications. J Pediatr Orthop. 2001; 21(1):4-8.

6. Flynn JM, Luedtke LM, Ganly TJ, Dawson J, Davidson $\mathrm{R}$, Dormans JP, et al. Comparison of Titanium Elastic Nails with Traction and a Spica Cast to Treat Femoral Fractures in Children. J Bone Joint Surg Am. 2004; 86(4):770-8.

7. Bhasker A. Mumbai treatment of long bone fractures in childrens by titanium elastic nailing. Ind J Orthop. 2005; 39(3):166-8.

8. Khazzam M, Tassone C, Liu XC, Lyon R, Freeto B. Schwab J, et al. Use of Flexible Intramedullary Nail Fixation in Treating Femur Fractures in Children. Am J Orthop. 2009; 38(3):49-55. 